\title{
A histological investigation of dental crown characters used in mosasaur phylogenetic analyses
}

\author{
Hallie P. Street ${ }^{1, \star}$, Aaron R. H. LeBlanc ${ }^{1,2}$, and Michael W. Caldwell ${ }^{1,3}$ \\ 'Department of Biological Sciences, University of Alberta, Edmonton, AB, Canada; hstreet@ualberta.ca; arl@ualberta.ca; \\ Michael.Caldwell@ualberta.ca \\ ${ }^{2}$ Centre for Oral, Clinical \& Translational Sciences, Faculty of Dentistry, Oral \& Craniofacial Sciences, King's College \\ London, London, UK \\ ${ }^{3}$ Department of Earth and Atmospheric Sciences, University of Alberta, Edmonton, AB, Canada
}

\begin{abstract}
Mosasaur researchers have used varieties of tooth crown ornamentation as diagnostic and phylogenetic characters for decades. Such tooth crown features include facets, flutes, striations, serrated carinae, and coarse anastomosing texture. This study investigates the relative contributions of dentine and enamel to the development of these dental characters and assesses homology statements between these structures. Histological analysis of isolated mosasaur teeth reveals that flutes and facets develop initially from the dentine, and the external enamel morphology we observe macroscopically mirrors the shape of the underlying dentine. Striations combine underlying contributions from the dentine with additional and irregular enamel deposition resulting strictly from amelogenesis. In both serrated carinae and anastomosing texture the Dentine-Enamel Junction is smooth, and these external ornamentations form exclusively through variations in enamel development. Based on these observations, we infer that flutes and facets form a morphological spectrum and should not be treated as separate phylogenetic characters. Conversely, striations develop differently than flutes and facets, and should therefore be treated as a distinct character. We recommend referring to serrations on mosasaur carinae as false denticulations to differentiate these enamel-only structures from true denticles possessing a dentine core. Anastomosing texture can also coincide with significant apical enamel thickening, both of which could be adaptations for processing harder prey, as they are in modern reptiles. Care must be taken when using tooth crown features as diagnostic or phylogenetic characters because seemingly different morphologies can have similar developmental origins, and tooth morphology can be more closely tied to diet than common ancestry.
\end{abstract}

\section{INTRODUCTION}

The modes of tooth attachment and replacement were among the features that first allowed nineteenth century naturalists to recognize that a giant fossil recovered from the phosphate mines in Maastricht, the Netherlands, represented an aquatic lizard and not a crocodile or a whale (Camper 1800; Cuvier 1808). Since then, the teeth of these extinct aquatic lizards, known as mosasaurs, have been studied extensively, and multiple histological analyses of their teeth have demonstrated how the dental tissues contribute to the modes of implantation and replacement (Caldwell 2007; Caldwell et al. 2003; LeBlanc et al. 2017; Luan et al. 2009; Rieppel and Kearney 2005; Zaher and
Rieppel 1999). Despite the thorough histological examination of mosasaur tooth attachment, examination of tooth crowns at the tissue level has focused primarily on microstructures of the dentine and enamel (Owocki and Madzia 2020; Sander 1999, 2000).

This lack of investigation is all the more surprising considering that tooth crown ornamentation figures prominently in the character lists used in phylogenetic analyses of Mosasauridae (Bell 1997; Bell and Polcyn 2005; Dortangs et al. 2002; LeBlanc et al. 2012; Palci et al. 2013; Simóes et al. 2017b). These characters include the presence or absence of facets, flutes, striations, serrated carinae, and anastomosing enamel textures on the outer tooth surface (Fig. 1A-E). When studying the distribution of these 

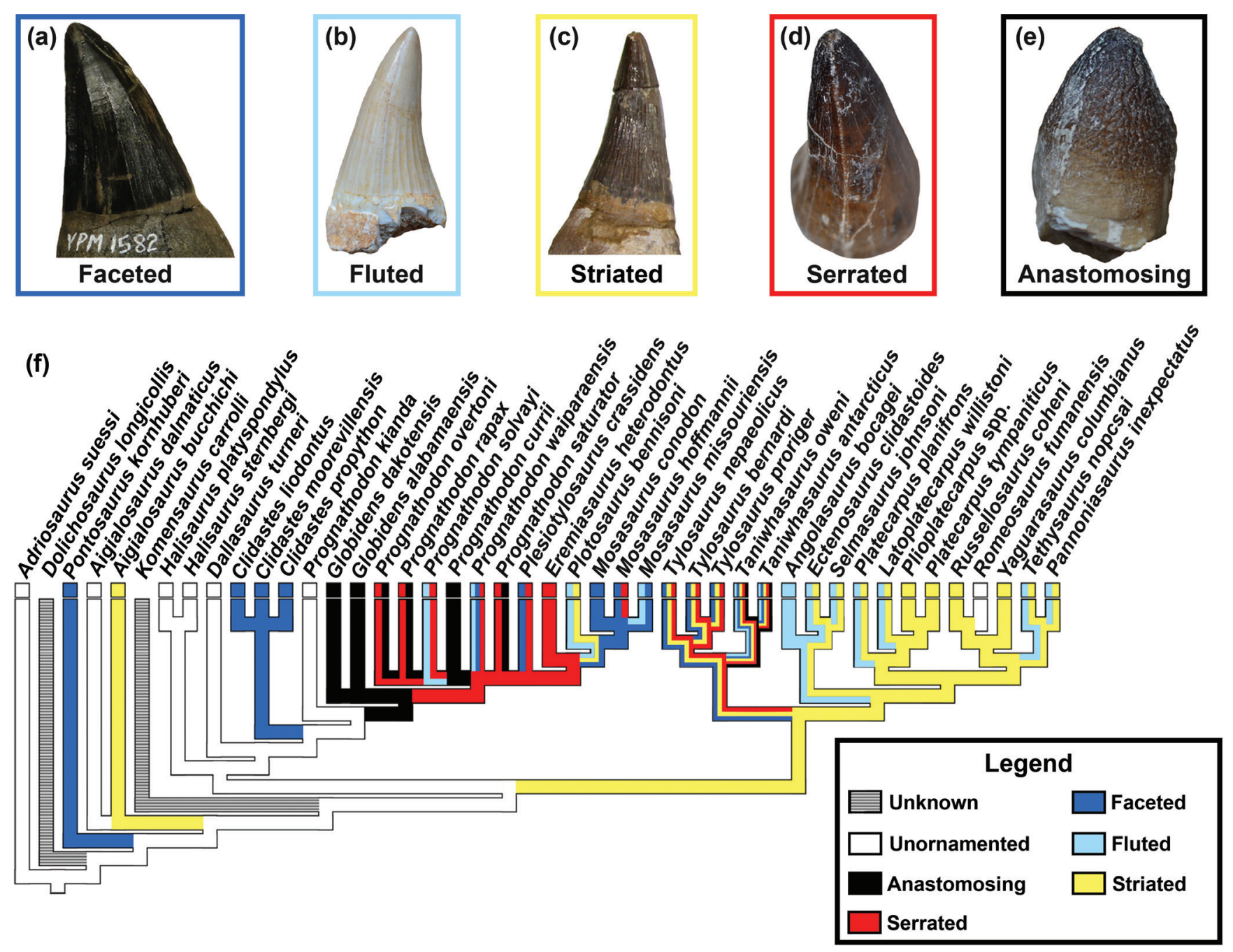

Figure 1. Mosasaur tooth crown characters examined in this study. A, faceted tooth; B, fluted tooth; C, lingually striated tooth; D, tooth with serrated carina; E, tooth with coarse anastomosing texture; F, phylogeny derived from Simões et al. (2017) with the distribution of these characters, as scored in previous analyses, mapped across the topology.

dental features across a clade, researchers need to be aware of possible homologies between the various characters. In the case of an extinct lineage like Mosasauridae, histology is the only way to investigate the developmental origins of such hard-tissue characters.

Different authors have used different terms for these tooth crown structures over the decades (e.g., striations were termed "vertical ridges" by Russell (1967:56), and Camp (1942:4) used "vertical striae" in place of flutes). The terminology has been slightly more consistent since the publication of Bell's (1997) character list, but even though the structures were described in that study, they were not illustrated. Between the inconsistent terminology and the lack of illustrations accompanying character lists, taxa have been mis-scored on tooth tissue features, such as scoring the derived mosasaurine Plotosaurus bennisoni as having striations (Fig. 1F). Hornung and Reich (2015) attempted to establish a new and hypothetically more consistent nomenclature for the apicobasal forms of ornamentation, but some of the structures they defined were considered to be ambiguous (Madzia 2020) and generally their classification has not been adopted by mosasaur researchers.

Based on the standardized terminology from Bell (1997) and others, we here define mosasaur enamel characters as follows (see also Table 1): facets are a series of flat surfaces around the circumference of a tooth crown separated by longitudinal ridges (Fig. 1A); flutes are visually similar to facets, but typically more closely spaced, and the enamel surface is concave between the longitudinal ridges (Fig. 1B); striations are fine and closely spaced grooves restricted to the base of a tooth crown, sometimes only developed on the lingual surface (Fig. 1C); serrations (sensu Bell 1997) are a series of notches along the length of a carina (Fig. 1D); anastomosing enamel texture is the most variable of 
Street et al. - Mosasaur tooth crown histology

these characters, but teeth with this character have a pebbled or finely wrinkled texture, particularly at the apex of the tooth crown (Fig. 1E).

Not only have these gross anatomical characters been used in phylogenetic analyses, but some have also been used to diagnose mosasaur taxa. For example, the presence of facets diagnoses Mosasaurus (Lingham-Soliar 1995; Russell 1967; Street and Caldwell 2017), while striations are diagnostic of Plioplatecarpini (Russell 1967), Russellosaurina (Polcyn and Bell 2005), or Plioplatecarpinae (Konishi and Caldwell 2011). Facets in mosasaurs have also been referred to as "prisms" (e.g., Russell 1967:64; Lingham-Soliar 1995:161). However, the word "prism" should be avoided in mosasaur dental anatomy, because this term is more frequently associated with prismatic enamel in mammals, including humans (Nanci 2003).

When these characters are mapped onto a phylogenetic tree of Mosasauridae (Fig. 1F), some of these tooth characters diagnose major taxa. For example, striations are found almost exclusively in the genera that comprise Polcyn and Bell's (2005) Russellosaurina. Conversely, facets and anastomosing textures are seen on the teeth of mosasaurines, with the coarse textures being restricted to Globidens spp. and Prognathodon spp. Flutes are found across Mosasauridae, and carinae have been reported (e.g., Bell 1997; Russell 1967; Simóes et al. 2017b) in all the included species except Tethysaurus nopcsai (Bardet et al. 2003) although serrations on the carinae are mostly restricted to mosasaurines (Fig. 1F). Exceptions to these general trends include reports of striations on teeth of Prognathodon solvayi (Dortangs et al. 2002) and Plotosaurus bennisoni (Camp 1942), and the presence of both serrations and facets in species of Tylosaurinae (Bullard and Caldwell 2010; Jiménez-Huidobro et al. 2019; Nicholls 1988). These exceptions could be the result of convergent evolution, which our observations indicate is most likely the case for the above-mentioned enamel ornamentation observed in tylosaurine species, but could also stem from the imprecise definitions of these descriptive terms when applied to mosasaur dental anatomy.

In order to better understand the potential homologies of these dental structures, they need to be examined at the histologic level because the external appearance of a tooth can be influenced not only by the development of the enamel that makes up the surface but also by the underlying dentine. Previous studies (Sander 1999, 2000) have documented the relationship between the dentine-enamel junction (DEJ) and the outer enamel surface (OES) across toothed reptiles for anatomical structures similar to those used in the mosasaur data set, but coarsely textured Globidens sp. teeth were the only identifiable representatives of Mosasauridae in those analyses. In previous stud- ies, longitudinal ornamentation, carinae, and serrations in other amniotes were most commonly formed by the dentine, were capped by enamel, and formed a complex DEJ (Brink et al. 2015; McCurry et al. 2019; Owocki and Madzia 2020; Sander 1999, 2000). Conversely, coarse enamel textures, also called wrinkles, were caused by differential rates of enamel deposition, based on the presence of a straight DEJ (Sander 1999, 2000). Similarly, the longitudinal ridges observed on sauropterygian teeth also develop through differential enamel deposition (Kear et al. 2017; McCurry et al. 2019; Sander 1999). Owocki and Madzia (2020:fig. 3c) illustrated the dentine and overlying enamel of a fluted russellosaurine tooth, but did not further investigate the relationship of these tissues across any other characters commonly used for mosasaur diagnoses or phylogenetic characters.

The purpose of this study is to investigate the five external tooth characters defined above and in Table 1 at the histologic level to determine the relative contribution of dentine and enamel to the external tooth anatomy. Understanding the development and relative tissue contribution in mosasaurid dental ornamentations can reveal whether the current hypotheses of homology are valid. With that information, it is possible to revise the characters for more accurate representation of tooth crown disparity in future phylogenetic analyses of Mosasauroidea.

\section{MATERIALS AND METHODS}

Seven isolated mosasaur teeth curated in the University of Alberta Vertebrate Palaeontology collections and Royal Tyrrell Museum were selected as morphotype representatives for preparation as thin sections. Facets were examined in a Mosasaurus sp. tooth (UALVP 57353), flutes were examined in Gavialimimus almaghribensis (MHNM.KHG.1231), striations were examined in two examples of Platecarpus tympaniticus (UALVP 55497, UALVP 57046), serrations were examined in Mosasaurus sp. (UALVP 57352) and in Prognathodon sp. (TMP 86.036.0463), and coarse texture was examined in Globidens simplex (MHNM.KHG.221) and Prognathodon sp. (TMP 86.036.0463).

With the exception of UALVP 55497, which is a tooth that had previously fallen off an articulated skull due to taphonomic damage, the specimens selected for histologic analysis are all shed teeth. Therefore, they were not freshly erupted and exhibit some wear to the enamel. Very little gross wear is evident on MHNM.KHG.1231. UALVP 57352 is broken at the base and apex, but the carinae show little visible wear. UALVP 57353 is broken at the apex but shows little additional wear. UALVP 55497 is broken toward the apex of the tooth and was reconstructed during preparation. However, the basal half of the tooth exhib- 
Table 1. Descriptions of the five types of tooth crown surface ornamentation discussed in this study, along with synonymous terminology used by previous authors.

\begin{tabular}{|c|c|c|}
\hline Term & Description & Synonyms \\
\hline Facet & $\begin{array}{l}\text { Broad, flat to subtly concave surfaces, separated by subtle, blunt, longitudinal } \\
\text { ridges. Not to be confused with wear facets. }\end{array}$ & $\begin{array}{l}\text { Prism faces (Hornung and Reich } \\
\text { 2015) }\end{array}$ \\
\hline Flute & $\begin{array}{l}\text { Narrow, concave surfaces, separated by pronounced, rounded to sharp longitudin- } \\
\text { al ridges. Also used for theropods (Hendrickx et al. 2015), ichthyosaurs (Maxwell } \\
\text { et al. 2012). Not to be confused with longitudinal ridges, as seen on plesiosaur } \\
\text { tooth crowns (Massare 1987; Kear et al. 2017). }\end{array}$ & $\begin{array}{l}\text { Facets, primary striae (Hornung } \\
\text { and Reich 2015) }\end{array}$ \\
\hline Striation & $\begin{array}{l}\text { Tightly spaced, fine grooves, usually restricted to the basolingual surface of the } \\
\text { crown. }\end{array}$ & $\begin{array}{l}\text { Basal striations (Hendrickx et al. } \\
\text { 2015), tertiary striae (Hornung } \\
\text { and Reich 2015) }\end{array}$ \\
\hline $\begin{array}{l}\text { Serration/False } \\
\text { denticulation }\end{array}$ & $\begin{array}{l}\text { Series of grooves or indentations, found on a carina. Not to be confused with } \\
\text { marginal undulations (Hendrickx et al. 2015) or true denticles (Brink et al. 2015; } \\
\text { Hendrickx et al. 2015). }\end{array}$ & $\begin{array}{l}\text { Transverse ribs (Massare 1987), } \\
\text { enamel crenulations (Brink et } \\
\text { al. 2015) }\end{array}$ \\
\hline $\begin{array}{l}\text { Anastomosing } \\
\text { texture }\end{array}$ & $\begin{array}{l}\text { Irregular texture, taking the form of bumps, pebbling, or vermiform or anasto- } \\
\text { mosing ridges, usually increasingly pronounced at apex of crown. }\end{array}$ & $\begin{array}{l}\text { Enamel texture (Hendrickx et } \\
\text { al. 2015), longitudinal sculpture } \\
\text { (Massare 1987), } \\
\text { wrinkles (Sander 1999) }\end{array}$ \\
\hline
\end{tabular}

its little visible wear. Some enamel has spalled off from MHNM.KHG.221, and this appears to be taphonomic rather than occlusal wear. TMP 86.036.0463 exhibits the most wear. It is broken at the base, a section of enamel spalled away near one carina (therefore the other carina was chosen for histological examination), and the apex exhibits a large wear facet.

Specimens were first photographed using a Nikon D5200 digital SLR camera. The specimens were then embedded in Castolite AP polyester resin, placed in a vacuum chamber to remove air bubbles, and then left to cure for at least 24 hours. The resin blocks containing the specimens were then cut using a Buehler Isomet 1000 wafer blade low-speed saw along the desired plane of section. Cross-sections were made near the base of each tooth for consistency because striations are only found on the basal region of tooth crowns. Plexiglas slides and the cut surfaces of the specimens were then hand ground using $600 \mu \mathrm{m}$ silicon carbide powder suspension on glass grinding plates to ensure both surfaces were smooth before the specimens were mounted on the Plexiglas slides using Scotch-Weld SF-100 cyanoacrylate. The specimens were then cut down to wafer thickness of approximately $700 \mu \mathrm{m}$ using the Buehler Isomet 1000 and subsequently ground with a Hillquist grinding cup. The final hand grinding and polishing were completed with $600 \mu \mathrm{m}$ and $1,000 \mu \mathrm{m}$ silicon carbide powder and water suspensions.

The thin sections were imaged using Nikon NIS ELEMENTS-D imaging software and a NikonDS-Fi3 camera mounted on a Nikon Eclipse E600POL polarizing microscope. Photomicrographs were taken under plane and cross-polarized light, and whole-section images were created using the stitching function of the software. Specimen preparation, sectioning, and imaging were conducted at the University of Alberta between March and August of 2017. All data that support the findings of this study are included in this article and are available from the authors upon request.

Institutional Abbreviations: MHNM, Museum of Natural History of Marrakech at Cadi Ayyad University, Marrakech, Morocco; TMP, Royal Tyrrell Museum of Palaeontology, Drumheller, Canada; UALVP, University of Alberta Laboratory for Vertebrate Palaeontology, Edmonton, Canada.

\section{RESULTS}

\section{General histology}

All of the mosasaur tooth crowns we examined were predominantly composed of dentine with a thin cap of clear enamel. The dentine is typical orthodentine with abundant and parallel dentine tubules, which would have housed the odontoblast processes in life (Nanci 2003) The enamel of most of the mosasaur teeth is thin, ranging from less than $30 \mu \mathrm{m}$ to $200 \mu \mathrm{m}$ (Sander 1999). When viewed under cross-polarized light, there is no evidence of prismatic microstructure in the enamel of the mosasaur teeth 
we examined (contra Chinsamy et al. 2012), but because this enamel microstructure is not the focus of our study the enamel was not examined via scanning electron microscope (e.g., Sander, 1997) to confirm the enamel type. In all cases where carinae are present, these structures are formed by the DEJ, though the degree to which the enamel does or does not thicken at the carinae varies taxonomically.

\section{Facets}

A transverse section near the base of a faceted Mosasaurus sp. tooth (Fig. 2A) reveals that the OES exactly mirrors the DEJ (Fig. 2B-D). The enamel and the dentine converge and form an obtuse angle, marking the ridge between neighboring facets. The DEJ is particularly visible when viewed under cross-polarized light (Fig. 2D). The thickness of the enamel does not vary greatly around the circumference of the tooth, increasing only slightly at the two carinae

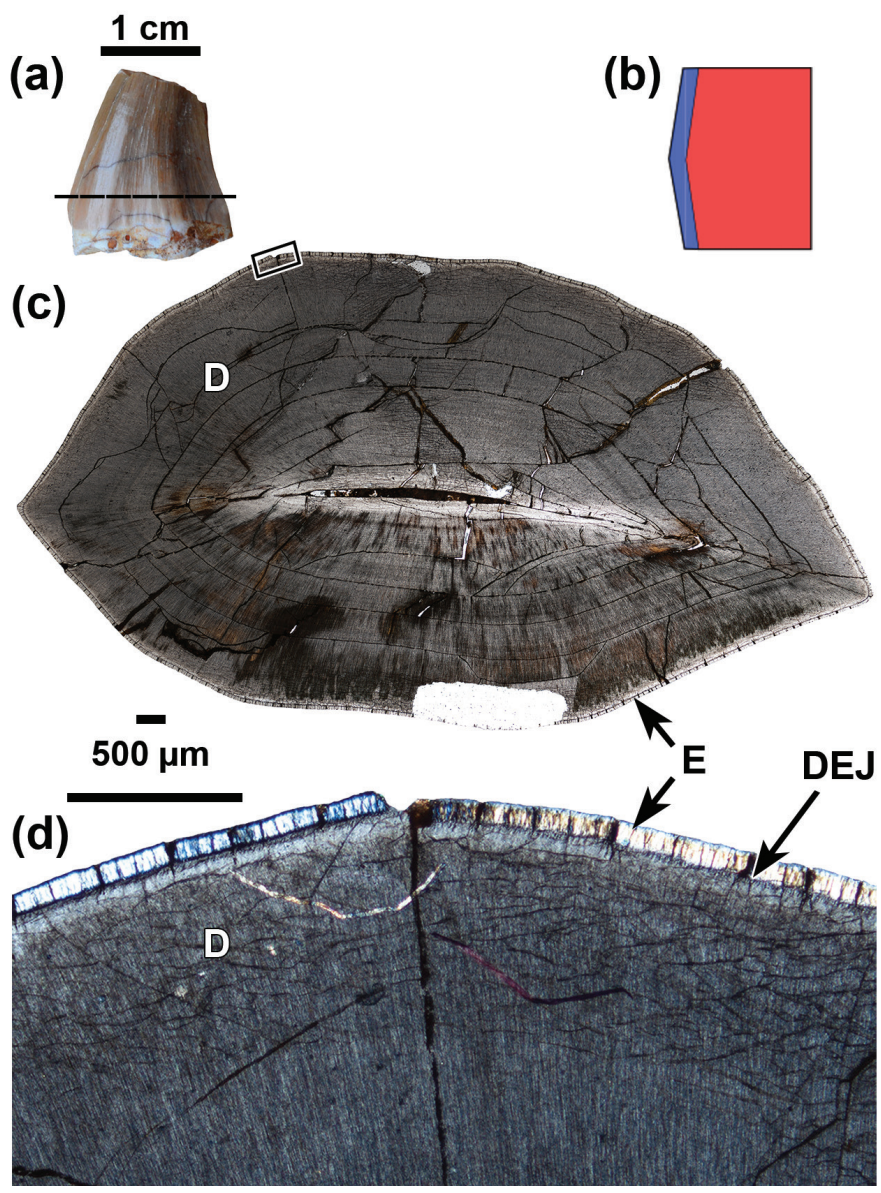

Figure 2. Anatomy of a faceted Mosasaurus sp. tooth (UALVP 57353). A, tooth in labial view with approximate plane of section indicated by the dashed line; B, schematic diagram illustrating the relationship between the enamel (blue) and the dentine (red); C, transverse section seen under plane polarized light. Box indicates the region magnified in (D). D, close-up of the dentine-enamel junction viewed under crossed polarized light. Abbreviations: D, dentine; DEJ, dentine-enamel junction; $\mathrm{E}$, enamel. and not appreciably at the ridges separating the facets. The enamel surface between the ridges is not completely planar but can actually be slightly concave, similar to the condition in fluted teeth (see below).

\section{Flutes}

A transverse section through the crown of a Gavialimimus almaghribensis tooth (Fig. 3A) reveals that flutes are generally similar to facets. The OES closely follows the DEJ (Fig. $3 \mathrm{~B}-\mathrm{D})$, with the ridge separating each enamel flute having a corresponding dentine core. The spacing of these undulations in the DEJ and OES is quite consistent. Unlike facets, the enamel of MHNM.KHG.1231 is slightly thicker at the crest of each ridge (mean $-92 \mu \mathrm{m}$ ) than in the troughs of each flute (mean $\sim 59 \mu \mathrm{m})$ (Fig. 3D). The flutes are more tightly spaced on the lingual side of the tooth than the labial side (Fig. 3C), and the disparity in enamel thickness between the crests and the troughs is greater on the lingual side of the tooth. This contrasts with previous observations

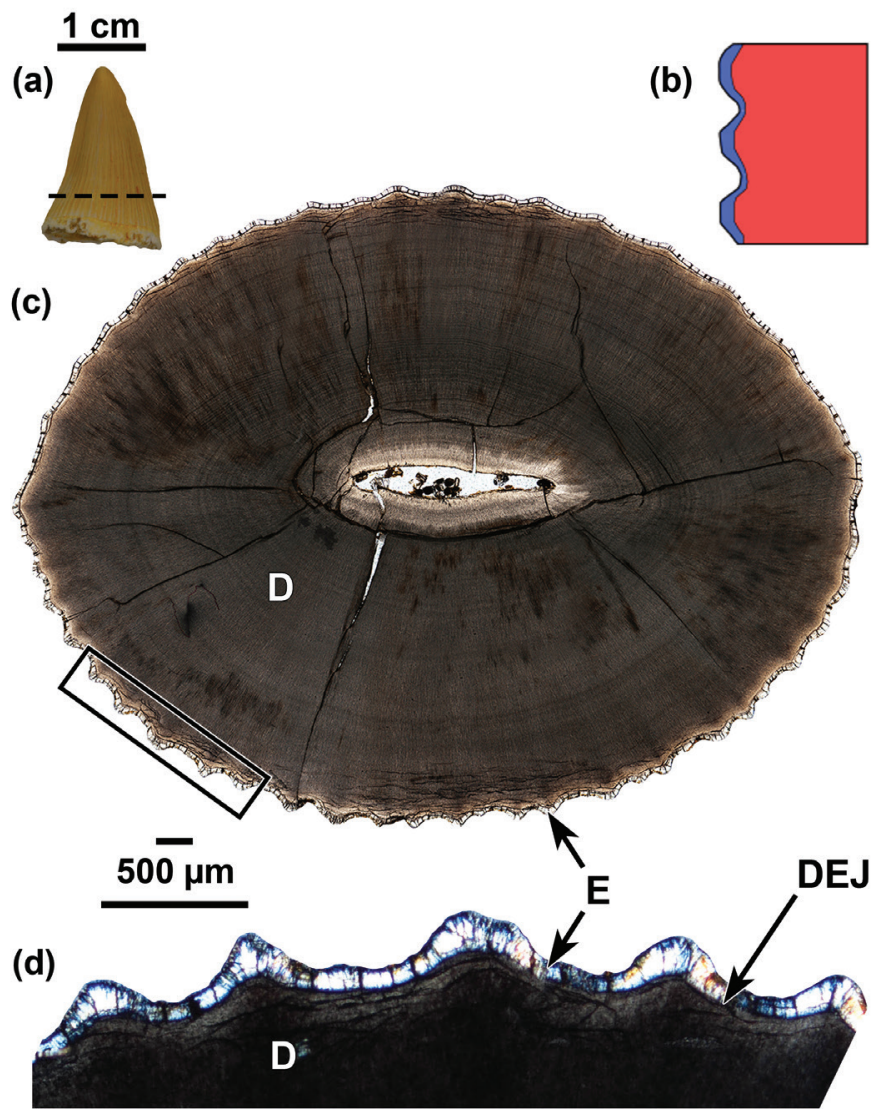

Figure 3. Anatomy of a fluted Gavialimimus almaghribensis tooth (MHNM.KHG.1231). A, tooth in labial view with approximate plane of section indicated by the dashed line; B, schematic diagram illustrating the relationship between the enamel (blue) and the dentine (red); C, transverse section seen under plane polarized light. Box indicates the region magnified in (D). D, close-up of the dentine-enamel junction viewed under crossed polarized light. Abbreviations: D, dentine; DEJ, dentine-enamel junction; $\mathrm{E}$, enamel. 
of consistent enamel thickness around the circumference of an indeterminate russellosaurine tooth bearing "mild longitudinal ridges" (Owocki and Madzia 2020:3). The increase in enamel thickness on the carinae is no greater than is seen on other ridges between flutes.

\section{Striations}

Striations are different from flutes and facets at the microscopic level. Examination of a transverse section taken near the base of a Platecarpus tympaniticus tooth crown (Fig. $4 \mathrm{~A})$ reveals that the OES does not directly correspond to the DEJ (Fig. 4B-D). The DEJ exhibits irregular folding around the lingual side of the tooth. The enamel layer varies in thickness, being vanishingly thin (minimum $-7 \mu \mathrm{m}$ ) in the grooves between folds in the DEJ and thickening to form sharp crests (maximum $-64 \mu \mathrm{m}$ ) between these folds

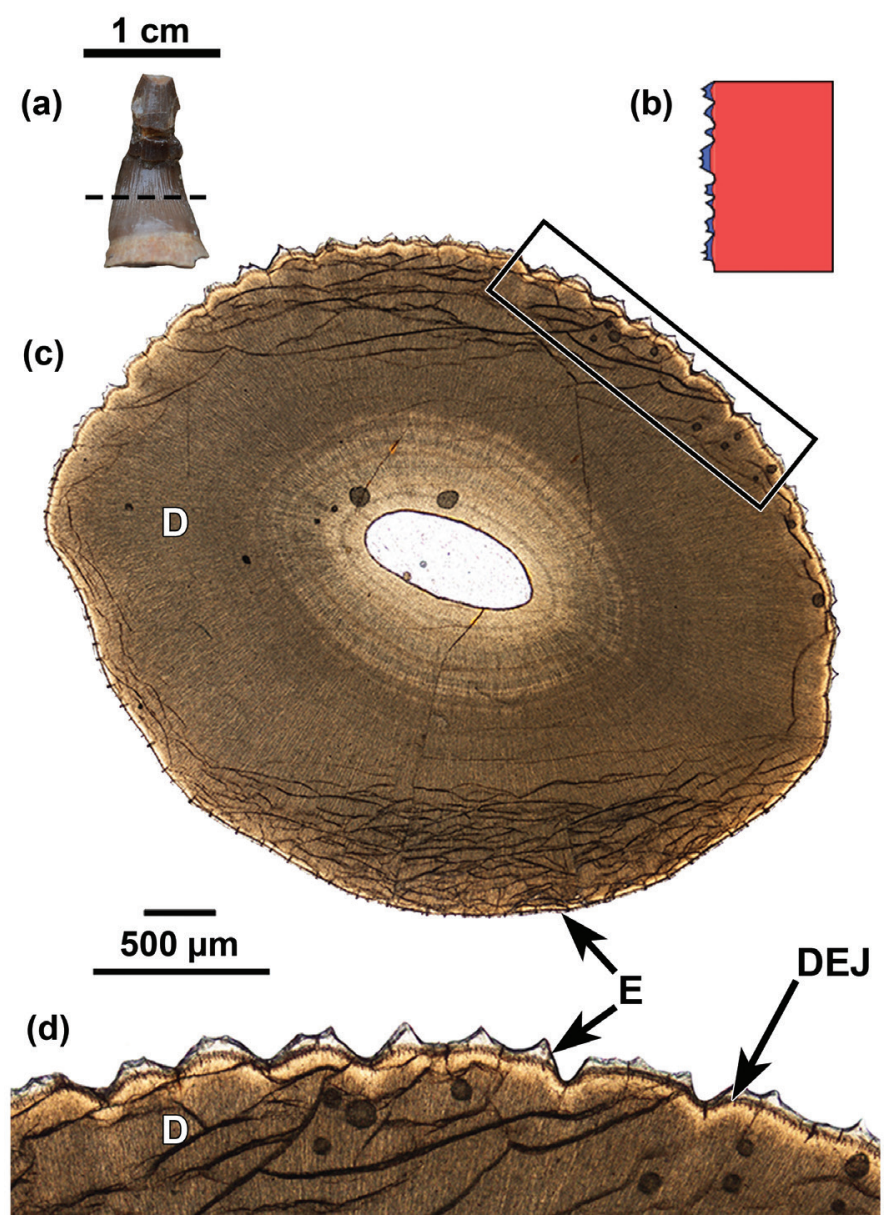

Figure 4. Anatomy of a striated Platecarpus tympaniticus tooth (UALVP 55497). A, tooth in lingual view with approximate plane of section indicated by the dashed line; B, schematic diagram illustrating the relationship between the enamel (blue) and the dentine (red); C, transverse section seen under plane polarized light. Box indicates the region magnified in (D). D, close-up of the dentine-enamel junction viewed under plane polarized light. Abbreviations: $D$, dentine; DEJ, dentine-enamel junction; $\mathrm{E}$, enamel.
(Fig. 4D). The number of enamel crests per dentine fold varies and does not correspond to the number of dentine folds. The spacing of both the folds in the DEJ and the enamel crests are more irregular in striations than in facets or flutes. On the labial side of the tooth, the DEJ is smooth and the thickness of the enamel is even.

\section{Serrations}

While carinae themselves are formed by enamel and dentine (the DEJ mirrors the OES along the carina) (Fig. 2C), a longitudinal section along a carina of Prognathodon sp. (Fig. 5A) shows that the serrations of mosasaur teeth have no contributions from dentine (Fig. 5B-D). The enamel increases in thickness apically along the carina from $\sim 198 \mu \mathrm{m}$ at the base of the crown to $-558 \mu \mathrm{m}$ where the
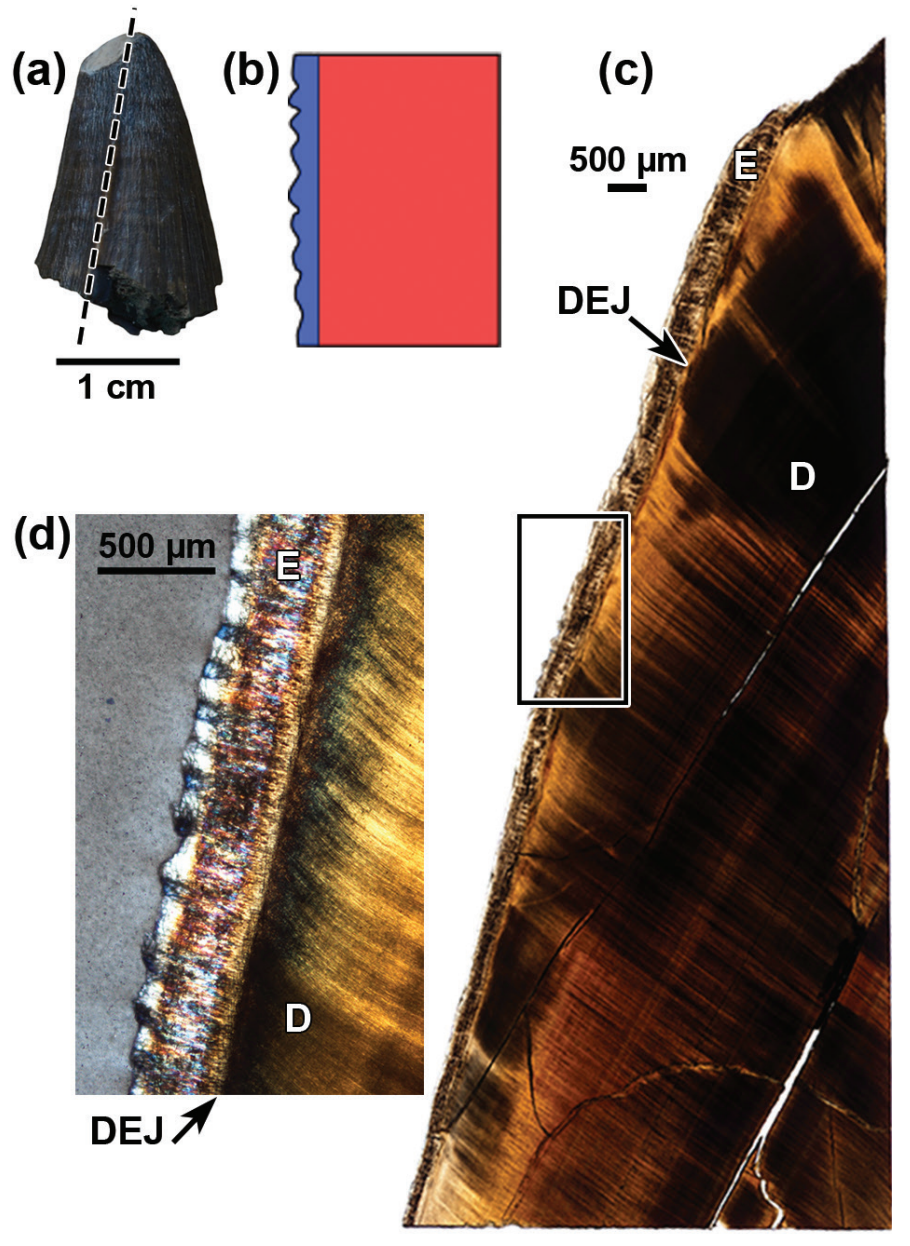

Figure 5. Anatomy of the false denticulations on a carina on a Prognathodon sp. tooth (TMP 86.036.0463). A, tooth in posterior view with approximate plane of section indicated by the dashed line; $B$, schematic diagram illustrating the relationship between the enamel (blue) and the dentine (red); C, longitudinal section seen under plane polarized light. Box indicates the region magnified in (D). D, close-up of the dentine-enamel junction viewed under crossed polarized light. Abbreviations: D, dentine; DEJ, dentine-enamel junction; $\mathrm{E}$, enamel 
Street et al. - Mosasaur tooth crown histology

carina terminates at a wear facet near the apex of the crown (Fig. 5C). The OES along the carina undulates, and the enamel texture is irregular under cross-polarized light, suggesting that the enamel microstructure is more convoluted and complex along serrated carinae (Fig. 5D). These types of serrations differ from the dentine-cored serrations in many other non-mammalian carnivores (Brink et al. 2015; Brink and Reisz 2014).

\section{Anastomosing texture}

A longitudinal section through the crown of a Globidens simplex tooth shows that the anastomosing texture is produced by differential thicknesses in the enamel only (Fig. 6A-D). The DEJ in this tooth is smooth, whereas the OES undulates irregularly (Fig. 6D). Moreover, the change in

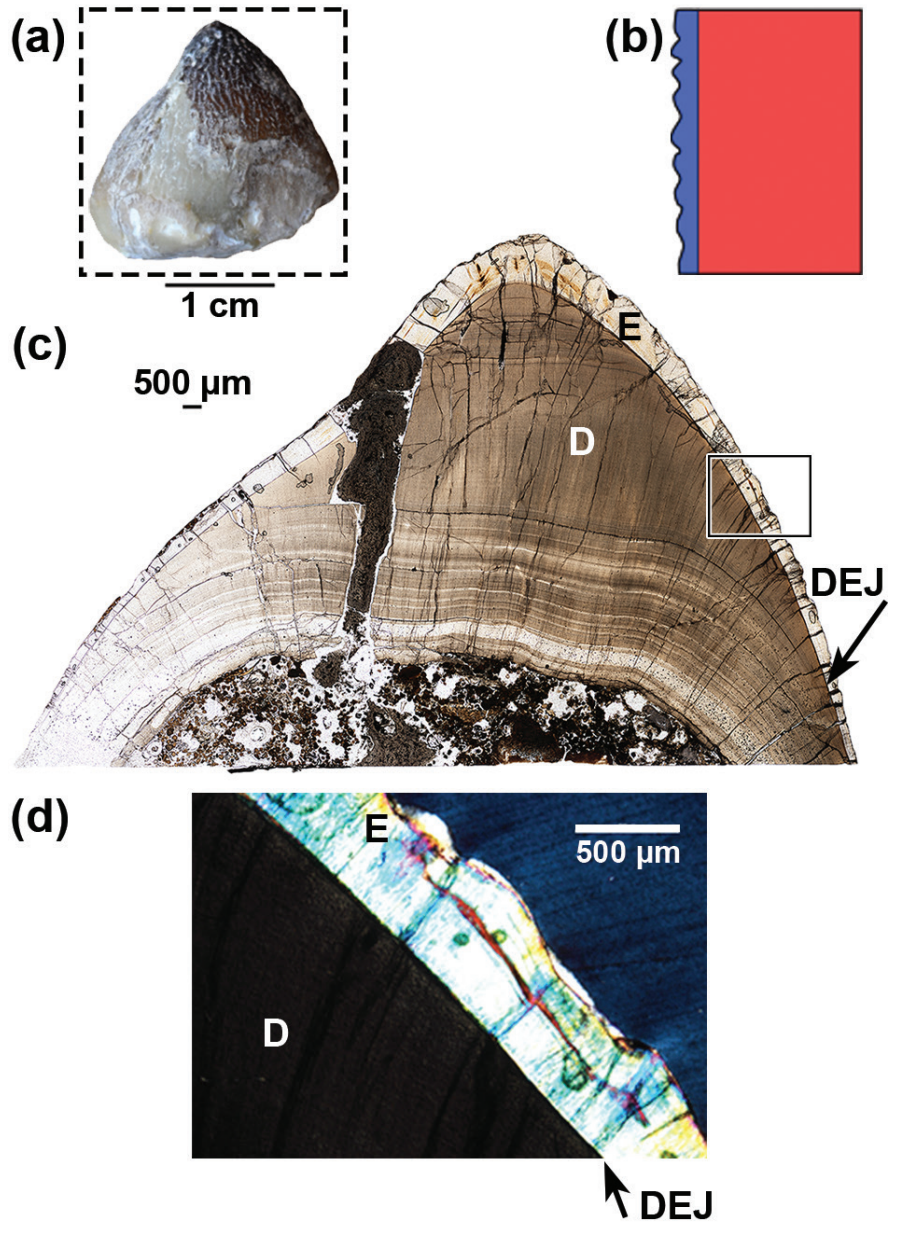

Figure 6. Anatomy of coarse anastomosing texture on a Globidens simplex tooth (MHNM.KHG.221). A, tooth in oblique view with approximate plane of section indicated by the dashed box; B, schematic diagram illustrating the relationship between the enamel (blue) and the dentine (red); C, longitudinal section seen under plane polarized light. Box indicates the region magnified in (D). D, closeup of the dentine-enamel junction viewed under crossed polarized light. Abbreviations: D, dentine; DEJ, dentine-enamel junction; E, enamel. enamel thickness from the base to the apex of the crown is particularly striking. Near the base of the crown the enamel is approximately $140 \mu \mathrm{m}$, and the enamel layer grows to a thickness of $1362 \mu \mathrm{m}$ at the apex (Fig. 6C). Anastomosing enamel structures adorn the entire surface of the tooth. The Prognathodon sp. tooth examined for its serrated carinae also exhibits anastomosing texture, though this texture is finer-scaled than that on the G. simplex tooth and does not extend to the base of the tooth crown (Fig. 5A). Similar to the $G$. simplex tooth, histological examination of the Prognathodon sp. tooth reveals that the DEJ does not contribute to the anastomosing texture, which is the result of differential enamel growth only. While the Prognathodon sp. tooth does show some apical thickening of the enamel, this increase in enamel thickness is moderate in comparison to that seen in the G. simplex specimen.

\section{DISCUSSION}

This histological examination of mosasaur tooth crowns provides evidence that various tooth ornamentations that are often used as phylogenetically informative characters develop in different manners and give differing signals of homology. The shapes of the DEJ and the OES reveal vital information about the timing and development of these tooth crown structures, as they do in other extant and extinct reptiles (Sander 1999). In all enamel-bearing teeth, the first hard tissue to form is the dentine, which develops centripetally towards the inner core of the tooth (Berkovitz and Shellis 2018; Nanci 2003). Once the contour of the tooth crown has been established within the dentine, the enamel either mirrors the underlying structure and forms parallel to the DEJ, or the enamel-producing ameloblasts form more complex structures independent of the underlying dentine and DEJ via differential enamel deposition (Sander 1999; Zahradnicek et al. 2014). The contours of the DEJ and OES in thin section therefore provide enough information to distinguish between crown ornamentations formed solely by amelogenesis and those that are formed prior to the formation of the first layers of dentine.

Faceted and fluted tooth crowns have been treated as separate characters in previous phylogenetic analyses (Bell 1997; Bell and Polcyn 2005; LeBlanc et al. 2012; Palci et al. 2013; Simóes et al. 2017b; Street 2016). However, the results of this study suggest that these two types of tooth crown ornamentation are actually different ends of a continuum of the same process of tooth crown development. Both of these structures are dictated by patterns of dentinogenesis, given that the DEJ contours the facets and flutes, with only minor differences in enamel thickness and shapes of the DEJ. This idea of a continuum between flutes and facets is further supported by observations of flutes 
and facets on single teeth (Fig. 7A, B) and taxa in which smaller individuals exhibit fluted teeth, whereas larger individuals exhibit faceted teeth (Fig. 7C, D). Flutes and facets therefore cannot be separate homologous characters because they fail the test of conjunction (Patterson 1982).
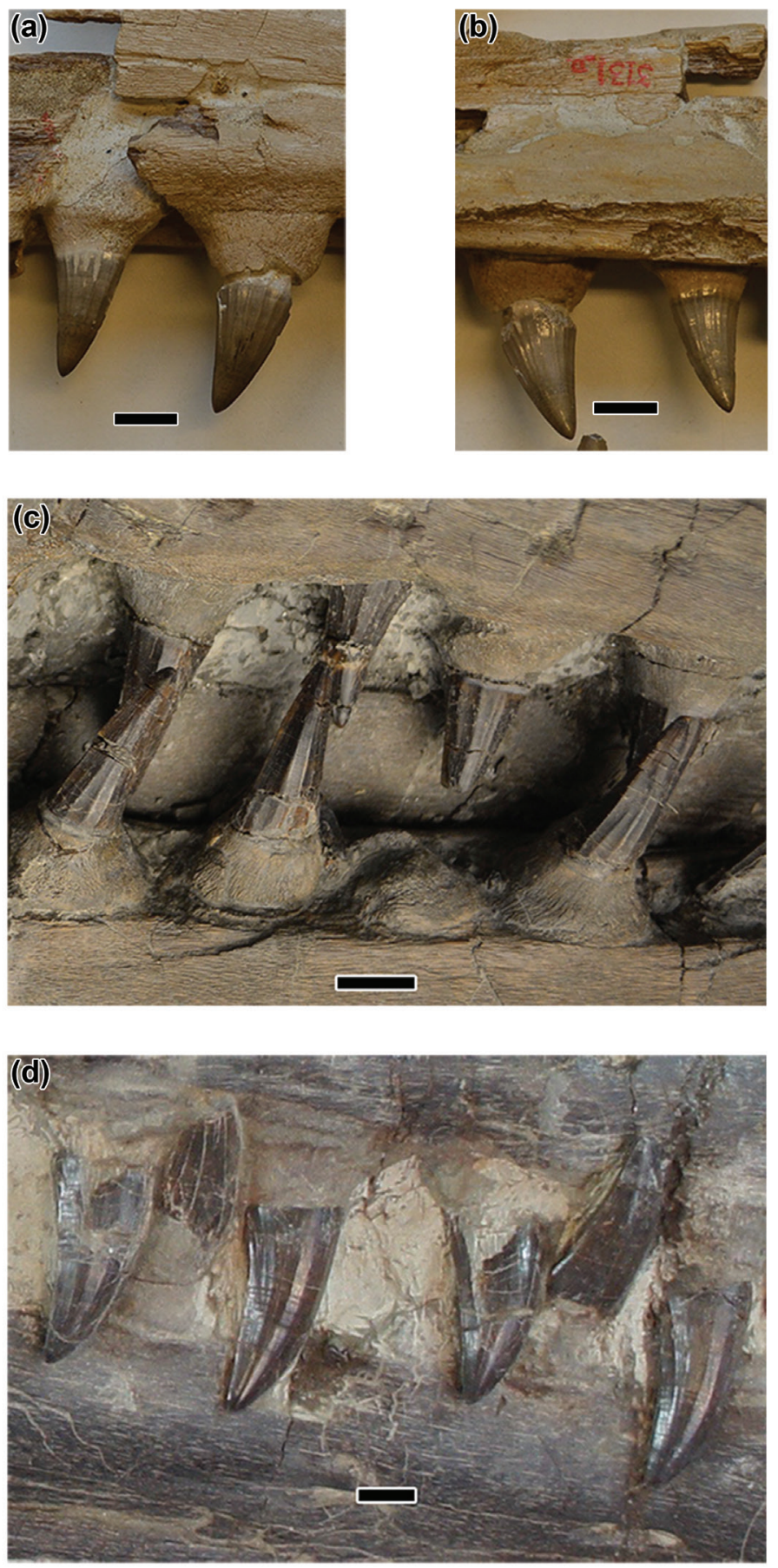

Figure 4. Co-occurrence of flutes and facets within a taxon. $A$, facets on the labial side of teeth in M. lemonnieri IRSNB $R$ 3131; B, flutes on the lingual side of the same teeth in $M$. lemonnieri IRSNB R 3131; C, flutes on teeth of a small individual of Mosasaurus missouriensis (TMP 2008.036.0001); D, facets on teeth of a large individual of $M$. missouriensis (TMP 2012.010.0001).
The observation of flutes on the teeth of small individuals and facets on those of larger individuals of the same taxon was made independently by multiple researchers (Lively 2018; Madzia 2020; Street 2016). Similarly, both Street (2016) and Madzia (2020) recognized the combination of flutes and facets occurring on a single tooth crown. While we consider these structures to likely have homologous developmental origins, we do not support the synonymization of the two terms (e.g., Hornung and Reich 2015) because the differences between flutes and facets continue to have taxonomic and ontogenetic utility. However, when including these forms of tooth crown ornamentation in future phylogenetic analyses, we recommend using a single character for the presence or absence of apico-basal ornamentation around the entire circumference of the tooth crown (see below).

The histology and development of analogous tooth crown structures in other reptiles are sometimes comparable with those of mosasaur teeth, but they can also differ fundamentally. For example, the development of flutes and facets in mosasaurs differs from that of the apicobasal ridges observed in derived sauropterygians. In the cases of Liopleurodon ferox, Polyptychodon interruptus, and Scanisaurus sp. the longitudinal ornamentation is produced entirely by differential enamel thickness, and the DEJ is smooth (Kear et al. 2017; McCurry et al. 2019; Sander 1999, 2000). A similar condition occurs in the longitudinal ribbing of the teeth in the mesosuchian crocodile Machimosaurus hugi, where the ridges along the crown are entirely composed of enamel (Sander 1999). Conversely, longitudinal ornamentation in ichthyosaurs, such as Ichthyosaurus sp., Stenopterygius sp., and Temnodontosaurus sp., appear to more closely resemble flutes and facets of mosasaurs in that these structures are dictated by the morphology of the DEJ (Maxwell et al. 2012; Sander 1999). In Temnodontosaurus sp., the ridges separating the flutes are more sharply pointed than those of Gavialimimus almaghribensis due to increased enamel deposition (Maxwell et al. 2012). In this respect, the fluted teeth of this ichthyosaur somewhat resemble the striations we observed in Platecarpus tympaniticus in combining sculpturing of the DEJ with differential amelogenesis.

Striations on mosasaur teeth can superficially resemble flutes and facets, but histology reveals that they are developmentally different from those structures. In the latter two types of ornamentation, the OES follows the shape of the DEJ, but this is not observed for striations. In this type of ornamentation, the dentine provides a base, but the enamel is deposited semi-independently. Multiple enamel crests can develop on a single dentine ridge (Fig. 4D). Therefore, striations are the result of a combination of initial dentinogenesis along major grooves followed by differential deposition of enamel crests during 
Street et al. - Mosasaur tooth crown histology

amelogenesis. Striations do not appear to be flutes formed by the DEJ with the addition of irregular enamel deposition. The undulations of the DEJ are fairly regular in the examined tooth of Gavialimimus almaghribensis, but in the cross-section of Platecarpus tympaniticus the folds of the DEJ are irregular. When compared to the rest of the circumference, the irregularities of the DEJ of P. tympaniticus resemble infoldings more than a regular undulation. Even though both the infoldings of the DEJ and the enamel crests are irregular in spacing and in depth/height, it seems the two develop in concert. If the two structures were entirely independent of each other, one might expect to see an enamel crest positioned in a groove in the DEJ, but this combination is never observed. Despite being smaller features compared to flutes and facets, these are developmentally the most complex forms of enamel ornamentation in mosasaurs. A previous attempt to standardize mosasaur tooth crown terminology (Hornung and Reich 2015) classified all longitudinal ornamentation as different orders of striae. This classification system has not been adopted in mosasaur tooth descriptions, and the results of our histological analysis demonstrate discrete developmental differences between flutes/facets (primary striae of Hornung and Reich 2015) and striations (tertiary striae of Hornung and Reich 2015). Considering that flutes, facets, and striations/striae are well-established terms in the mosasaur literature, we do not propose changes to this nomenclature. We also do not adopt the use of "distinct and indistinct apicobasal ridges" suggested by Madzia (2020:1342), or "apicobasal ridges" for all forms of longitudinal ornamentation (after McCurry et al. 2019:246) but we hope our study clarifies the differences between these forms of ornamentation. The presence or absence of striations should therefore remain as a separate character in future phylogenetic analysis due to the independence of striation development from flutes and facets.

Carinae are the raised cutting edges formed by the "pinching out" of the DEJ, though the enamel can be slightly thicker on the carinae than around the rest of the circumference of the crown (Fig. 2C). However, our histological sections show that serrations along the length of the carinae of mosasaur tooth crowns are composed entirely of enamel and are therefore the product of amelogenesis. Because the serrations are formed only by irregular enamel deposition, they are quite prone to wear, thus making this feature difficult to evaluate from worn or abraded tooth crowns. Even though we did not have a tylosaurine tooth available for histological analysis, observation of the external gross morphology found no distinct differences between the serrated carinae of tylosaurines and mosasaurines. All of the serrated carinae on mosasauroid teeth that we have observed appear similar at the macroscopic level.

Unlike the serrations seen in other groups of reptiles, including dinosaurs and vananoid squamates (Brink et al.
2015; Hendrickx et al. 2015), the serrations on mosasaur teeth are not true denticles because they lack dentine cores. In this respect, the serrations in mosasaurs are less like the denticles of theropod dinosaurs and more similar to those seen in some crocodiles and in Smilodon sp. (Brink et al. 2015; Sander 1999). However, unlike in mammals, mosasaurs had thin, wear-prone aprismatic enamel, suggesting that mosasaur serrations could wear away quickly during the lifespan of a tooth. To distinguish between these variations in serration form, which in turn reflect different developmental patterns, we propose that the type of serrations exhibited by mosasaurs - lacking dentine cores - be called false denticulations after Prasad and de Lapparent de Broin (2002). This terminology better communicates the fact that the enamel coating the tooth provides the external ornamentation, whereas the underlying dentine of the carina is smooth.

The coarse, anastomosing texture varies in pattern and extent of crown coverage across different taxa of mosasaurs. In both the Prognathodon sp. and the Globidens simplex teeth sectioned for this study, the anastomosing texture is the result of amelogenesis with no contribution from the underlying dentine. This independence between the DEJ and the OES has previously been reported in Dracaena guianensis, Varanus niloticus, Globidens alabamensis, and several other extinct and extant reptiles with bulbous teeth (Sander 1999, 2000). Durophagous ichthyosaurs, for example, also exhibit textured enamel, and with the exception of Tholodus schmidi, the DEJ is smooth; the texture of the OES is solely due to differential amelogenesis (Sander 1999). At present, the function of such coarse enamel texture in mosasaur teeth is unclear, however some authors have suggested that it may serve as a structural support for the enamel in hard-biting animals (Rieppel and Labhardt 1979).

Developmentally, the false denticulations and anastomosing enamel texture are produced by the same process. In both cases, fine-scale irregularities in enamel deposition produce these crown ornamentations. Reptilian enamel is typically quite thin, ranging from $25-50 \mu \mathrm{m}$ (Owocki and Madzia 2020; Sander 1999, 2000), and apical thickening of the enamel has been previously reported (Owocki and Madzia 2020; Sander 1999). The enamel layer at the apex of the sampled Globidens simplex tooth crown (Fig. 6C) is particularly noteworthy in that it exceeds one millimeter in thickness, which is unusually thick for a reptile (Sander 1999, 2000), though not as thick as has been observed in the durophagous ichthyosaur Omphalosaurus sp. (Wintrich et al. 2017). Among modern squamates, the tupinambine teiid Dracaena guianensis and the varanid Varanus niloticus have convergently evolved a bulbous crushing dentition, similar to that of Globidens spp. In both of these extant squamates, the enamel is thick (exceeding $500 \mu \mathrm{m}$ in many 
cases) and possesses the same coarse enamel ornamentation along the crown as in Globidens (Sander 1999). Some species of Prognathodon and all species of Globidens are also interpreted as having been durophagous, so it is possible that the thickened enamel is an adaptation for this feeding style. The two-fold difference in enamel thickness between Globidens and extant durophagous squamates may simply be a product of absolute size differences of the teeth.

\section{CHARACTER CONSTRUCTION}

This study was inspired by a query about the possibility of homology between flutes and facets in the context of characters for phylogenetic analyses of Mosasauridae. Through our histological analyses we found no evidence to contradict a hypothesis of homology for flutes and facets. Because these forms of ornamentation appear to be different ends of a developmental spectrum, we propose combining these features in future phylogenetic analyses. Such a new character could read: Marginal teeth, longitudinal (apicobasal) ornamentation, entire circumference of tooth: (0) absent; (1) present.

We do not recommend the use of a multi-state character including the states smooth enamel, faceted enamel, and fluted enamel. Considering that the presence of flutes and facets can change throughout ontogeny, and that flutes and facets have been observed not only in the same individual animal, but on the same tooth, these two types of ornamentation fail the test of conjunction (Patterson 1982); therefore they cannot belong to an evolutionary transformation series, which is implied by multi-state characters (Simóes et al. 2017a). This is not to discount the utility of the terms facets and flutes in descriptions or diagnoses, but the developmental relationship between these structures precludes their separation in a cladistic context. The other characters we reviewed (striations, false denticulations, and anastomosing texture) do not appear to be directly linked developmentally, so we do not propose combining them under any new hypotheses of homology.

Care should always be taken when using tooth crown ornamentation as characters in phylogenetic analyses or as the basis for taxonomic differentiation. Tooth ornamentation and underlying shape are adaptations for prey type and processing, and these features exhibit a great deal of convergence (Massare 1987). Tooth characters alone can therefore be poor candidates for uniting clades, because they are more likely tied to diet than to common ancestry (LeBlanc et al. 2012; Strong et al. 2020). The histological approach we applied in this study could be applied to other groups of reptiles where tooth crown ornamentation has been considered to be phylogenetically informative. A clearer understanding of how development and histology contribute to gross morphological characters is essential for accurate evaluation of these features and should also reduce the complications and confusion arising from poorly defined characters and misidentification of structures.

\section{ACKNOWLEDGEMENTS}

ARHL wishes to thank the Killam Trust for an Izaak Walter Killam Memorial Postdoctoral Fellowship and the Natural Sciences and Engineering Research Council of Canada for a Postdoctoral Fellowship. MWC is funded by a Chair's Research Allowance and a Natural Sciences and Engineering Research Council of Canada Discovery Grant (\#234538).

\section{Availability of Data}

The histologic thin sections that support the findings of this study are available from the corresponding author upon reasonable request.

\section{Author Contributions}

HPS contributed to the conceptualization, investigation, writing - original draft, and visualization for this study. ARHL contributed to the methodology, investigation, resources, and writing - review and editing. MWC contributed to the conceptualization, resources, writing - review and editing, supervision, and funding acquisition for this study.

\section{LITERATURE CITED}

Bardet, N., X. Pereda Suberbiola, and N.-E. Jalil. 2003. A new mosasauroid (Squamata) from the Late Cretaceous (Turonian) of Morocco. Comptes Rendus Palevol 2:607-616.

Bell, G.L. Jr.1997. A phylogenetic revision of North American and Adriatic Mosasauroidea; pp. 293-332 in J.M. Callaway and E.L. Nicholls (eds.), Ancient Marine Reptiles. Academic Press, San Diego.

Bell, G.L. Jr., and M.J. Polcyn. 2005. Dallasaurus turneri, a new primitive mosasauroid from the middle Turonian of Texas and comments on the phylogeny of Mosasauridae (Squamata). Geologie En Mijnbouw/Netherlands Journal of Geosciences 84:177-194.

Berkovitz, B., and P. Shellis. 2018. The Teeth of Mammalian Vertebrates. Elsevier, Amsterdam, 342 pp.

Brink, K.S., and R.R. Reisz. 2014. Hidden dental diversity in the oldest terrestrial apex predator Dimetrodon. Nature Communications 5:1-9.

Brink, K.S., R.R. Reisz, A.R.H. LeBlanc, R.S. Chang, Y.C. Lee, C.C. Chiang, T. Huang, and D.C. Evans. 2015. Developmental and evolutionary novelty in the serrated teeth of theropod dinosaurs. Scientific Reports 5:12338.

Bullard, T.S., and M.W. Caldwell. 2010. Redescription and rediagnosis of the tylosaurine mosasaur Hainosaurus pembinensis Nicholls, 1988, as Tylosaurus pembinensis (Nicholls, 1988). Journal of Vertebrate Paleontology 30:416-426. 
Caldwell, M.W. 2007. Ontogeny, anatomy and attachment of the dentition in mosasaurs (Mosasauridae: Squamata). Zoological Journal of the Linnean Society 149:687-700.

Caldwell, M.W., L.A. Budney, and D.O. Lamoureux. 2003. Histology of tooth attachment tissues in the Late Cretaceous mosasaurid Platecarpus. Journal of Vertebrate Paleontology 23:622-630.

Camp, C.L. 1942. California mosasaurs. Memoirs of the University of California 13:1-68.

Camper, A.G. 1800. Sur les ossemens fossiles de la montagne de St. Pierre, à Maëstricht. Journal de Physisque, de Chimie et d'Histoire Naturelle 51:278-291.

Chinsamy, A., C. Tonoğlu, and D.B. Thomas. 2012. Dental microstructure and geochemistry of Mosasaurus hoffmanni (Squamata: Mosasauridae) from the Late Cretaceous of Turkey. Bulletin de La Societe Geologique de France 183:85-92.

Cuvier, G. 1808. Sur le grand animal fossile des carrières de Maestricht. Annales Du Museum d'Histoire Naturelle 12:145-176.

Dortangs, R.W., A.S. Schulp, E.W.A. Mulder, J.W.M. Jagt, H.H.G. Peeters, and D.T. de Graaf. 2002. A large new mosasaur from the Upper Cretaceous of The Netherlands. Geologie En Mijnbouw/Netherlands Journal of Geosciences 81:1-8.

Hendrickx, C., O. Mateus, and R. Araújo. 2015. A proposed terminology of theropod teeth (Dinosauria, Saurischia). Journal of Vertebrate Paleontology 35:e982797.

Hornung, J.J., and M. Reich. 2015. Tylosaurine mosasaurs (Squamata) from the Late Cretaceous of northern Germany. Geologie En Mijnbouw/Netherlands Journal of Geosciences 94:55-71.

Jiménez-Huidobro, P., M.W. Caldwell, I. Paparella, and T.S. Bullard. 2019. A new species of tylosaurine mosasaur from the upper Campanian Bearpaw Formation of Saskatchewan, Canada. Journal of Systematic Palaeontology 17:849-864.

Kear, B.P., D. Larsson, J. Lindgren, and M. Kundrát. 2017. Exceptionally prolonged tooth formation in elasmosaurid plesiosaurians. PLoS ONE 12:1-14.

Konishi, T., and M.W. Caldwell. 2011. Two new plioplatecarpine (Squamata, Mosasauridae) genera from the Upper Cretaceous of North America, and a global phylogenetic analysis of plioplatecarpines. Journal of Vertebrate Paleontology 31:754-783.

LeBlanc, A.R.H., M.W. Caldwell, and N. Bardet. 2012. A new mosasaurine from the Maastrichtian (Upper Cretaceous) phosphates of Morocco and its implications for mosasaurine systematics. Journal of Vertebrate Paleontology 32:82-104.

LeBlanc, A.R.H., D.O. Lamoureux, and M.W. Caldwell. 2017. Mosasaurs and snakes have a periodontal ligament: timing and extent of calcification, not tissue complexity, determines tooth attachment mode in reptiles. Journal of Anatomy 231:869-885.

Lingham-Soliar, T. 1995. Anatomy and functional morphology of the largest marine reptile known, Mosasaurus hoffmanni (Mosasauridae, Reptilia) from the Upper Cretaceous, upper Maastrichtian of the Netherlands. Philosophical Transactions of the Royal Society B: Biological Sciences 347:155-172.
Lively, J.R. 2018. Taxonomy and historical inertia: Clidastes (Squamata: Mosasauridae) as a case study of problematic paleobiological taxonomy. Alcheringa 42:516-527.

Luan, X., C. Walker, S. Dangaria, Y. Ito, R. Druzinsky, K. Jarosius, H. Lesot, and O. Rieppel. 2009. The mosasaur tooth attachment apparatus as paradigm for the evolution of the gnathostome periodontium. Evolution and Development 11:247-259.

Madzia, D. 2020. Dental variability and distinguishability in Mosasaurus lemonnieri (Mosasauridae) from the Campanian and Maastrichtian of Belgium, and implications for taxonomic assessments of mosasaurid dentitions. Historical Biology 32:1340-1354.

Massare, J.A. 1987. Tooth morphology and prey preference of Mesozoic marine reptiles. Journal of Vertebrate Paleontology 7:121-137.

Maxwell, E.E., M.W. Caldwell, and D.O. Lamoureux. 2012. Tooth histology, attachment, and replacement in the Ichthyopterygia reviewed in an evolutionary context. Palaontologische Zeitschrift 86:1-14.

McCurry, M.R., A.R. Evans, E.M.G. Fitzgerald, C.R. McHenry, J. Bevitt, and N.D. Pyenson. 2019. The repeated evolution of dental apicobasal ridges in aquatic-feeding mammals and reptiles. Biological Journal of the Linnean Society 127:245-259.

Nanci, A. 2003. Ten Cate's Oral Histology: Development, Structure, and Function. Mosby, St. Louis, 379 pp.

Nicholls, E.L. 1988. The first record of the mosasaur Hainosaurus (Reptilia: Lacertilia) from North America. Canadian Journal of Earth Sciences 25:1564-1570.

Owocki, K., and D. Madzia. 2020. Predatory behaviour in mosasaurid squamates inferred from tooth microstructure and mineralogy. Cretaceous Research 111:104430.

Palci, A., M.W. Caldwell, and C.A. Papazzoni. 2013. A new genus and subfamily of mosasaurs from the Upper Cretaceous of northern Italy. Journal of Vertebrate Paleontology 33:599-612.

Patterson, C. 1982. Morphological characters and homology; pp. 21-74 in K.A. Joysey and A.E. Friday (eds.), Problems of Phylogenetic Reconstruction. Academic Press, London and New York.

Polcyn, M.J., and G.L. Bell Jr. 2005. Russellosaurus coheni n. gen., n. sp., a 92 million-year-old mosasaur from Texas (USA), and the definition of the parafamily Russellosaurina. Geologie En Mijnbouw/Netherlands Journal of Geosciences 84:321-333.

Prasad, G.V.R., and F. de Lapparent de Broin. 2002. Late Cretaceous crocodile remains from Naskal (India): comparisons and biogeographic affinities. Annales de Paléontologie 88:19-71.

Rieppel, O., and L. Labhardt. 1979. Mandibular mechanics in Varanus niloticus. Herpetologica 35:158-163.

Rieppel, O., and M. Kearney. 2005. Tooth replacement in the Late Cretaceous mosasaur Clidastes. BioOne 39:688-692.

Russell, D.A. 1967. Systematics and morphology of American mosasaurs. Bulletin of the Peabody Museum of Natural History, Yale University 23:1-240. 
Sander, P.M. 1997. Teeth and jaws; pp. 717-725 in P.J. Currie and K. Padian (eds.), Encyclopedia of Dinosaurs. Academic Press, San Diego.

Sander, P.M. 1999. The microstructure of reptilian tooth enamel: terminology, function, and phylogeny. Münchner Geowissenschaftliche Abhandlungen (A) 38:1-102.

Sander, P.M. 2000. Prismless enamel in amniotes: Terminology, function and evolution; pp. 92-106 in M.F. Teaford, M.M. Smith, and M.W.J. Ferguson (eds.), Development, Function and Evolution of Teeth. Cambridge University Press, Cambridge.

Simôes, T.R., M.W. Caldwell, A. Palci, and R.L. Nydam. 2017a. Giant taxon-character matrices: Quality of character constructions remains critical regardless of size. Cladistics 33:198-219.

Simóes, T.R., O. Vernygora, I. Paparella, P. Jiménez-Huidobro, and M.W. Caldwell. 2017b. Mosasauroid phylogeny under multiple phylogenetic methods provides new insights on the evolution of aquatic adaptations in the group. PLoS ONE 12:1-20.

Street, H.P. 2016. A re-assessment of the genus Mosasaurus (Squamata: Mosasauridae). PhD Dissertation, Department of Biological Sciences, University of Alberta, Edmonton, AB, Canada. 316 pp.
Street, H.P., and M.W. Caldwell. 2017. Rediagnosis and redescription of Mosasaurus hoffmannii (Squamata: Mosasauridae) and an assessment of species assigned to the genus Mosasaurus. Geological Magazine 154:521-557.

Strong, C.R.C., M.W. Caldwell, T. Konishi, and A. Palci. 2020. A new species of longirostrine plioplatecarpine mosasaur (Squamata: Mosasauridae) from the Late Cretaceous of Morocco, with a re-evaluation of the problematic taxon 'Platecarpus' ptychodon. Journal of Systematic Palaeontology 1-36.

Wintrich, T., S. Hayashi, A. Houssaye, Y. Nakajima, and P.M. Sander. 2017. A Triassic plesiosaurian skeleton and bone histology inform on evolution of a unique body plan. Science Advances 3:e1701144.

Zaher, H., and O. Rieppel. 1999. Tooth implantation and replacement in squamates, with special reference to mosasaur lizards and snakes. American Museum Noviates 3271:1-19.

Zahradnicek, O., M. Buchtova, H. Dosedelova, and A.S. Tucker. 2014. The development of complex tooth shape in reptiles. Frontiers in Physiology 5:1-7. 